\title{
The role of unhealthy lifestyles in the incidence and persistence of depression: a longitudinal general population study in four emerging countries
}

\author{
Maria Cabello ${ }^{1}$, Marta Miret ${ }^{1,2}$, Francisco Felix Caballero ${ }^{1,2}$, Somnath Chatterij ${ }^{3}$, Nirmala Naidoo ${ }^{3}$, Paul Kowal $^{3,4}$,
} Catherine D'Este ${ }^{5}$ and Jose Luis Ayuso-Mateos ${ }^{1,2,6^{*}}$

\begin{abstract}
Background: Unhealthy lifestyles and depression are highly interrelated: depression might elicit and exacerbate unhealthy lifestyles and people with unhealthy lifestyles are more likely to become depressed over time. However, few longitudinal evidence of these relationships has been collected in emerging countries. The present study aims i) to analyse whether people with unhealthy lifestyles are more likely to develop depression, and ii) to examine whether depressed people with unhealthy lifestyles are more likely to remain depressed. A total of 7908 participants from Ghana, India, Mexico and Russia were firstly evaluated in the World Health Organization's Study on Global AGEing and Adult Health (SAGE) Wave 0 (2002-2004) and re-evaluated in 2007-2010 (Wave 1). Data on tobacco use, alcohol drinking and physical activity, were collected. Logistic regressions models were employed to assess whether baseline unhealthy lifestyles were related to depression in Wave 1, among people without 12-month depression in Wave 0 and any previous lifetime diagnosis of depression, and to 12-month depression at both study waves (persistent depression).

Results: Baseline daily and non-daily smoking was associated with depression in Wave 1. Low physical activity and heavy alcohol drinking were associated with persistent depression.

Conclusions: Unhealthy lifestyles and depression are also positively related in emerging countries. Smoking on a daily and non-daily basis was longitudinally related to depression. Depressed people with low physical activity and with heavy drinking patterns were more likely to become depressed over time. Several interpretations of these results are given. Further studies should check whether a reduction of these unhealthy lifestyles leads to lower depression rates and/or to a better clinical prognosis of depressed people.
\end{abstract}

Keywords: Depression, Longitudinal study, Middle-income countries, Lifestyles

\section{Background}

According to World Health Organization (WHO), tobacco use, excessive alcohol drinking and physical inactivity are important modifiable risk factors for mortality and burden in the world [1]. These factors have been traditionally studied in the field of non-communicable diseases such as cancer, diabetes or heart attacks [2]. However, unhealthy

\footnotetext{
* Correspondence: joseluis.ayuso@uam.es

${ }^{1}$ Centro de Investigación Biomédica en Red de Salud Mental. CIBERSAM, Instituto de Salud Carlos III, Madrid, Spain

${ }^{2}$ Department of psychiatry, Universidad Autónoma de Madrid, Madrid, Spain

Full list of author information is available at the end of the article
}

lifestyles are also related to mental health [3]. Particularly, people with depression frequently smoke, have a higher prevalence of excessive alcohol drinking and are more physically inactive [4]. The relationships between depression and unhealthy lifestyles are probably reciprocal. Firstly, depression might elicit and exacerbate unhealthy lifestyles. Depression is related to the onset of physically inactivity [5], to the development alcohol use disorders [6] and to an increase in the risk of progression to daily smoking [7]. Some authors argue that depression drives to unhealthy lifestyles because people with depression use them as a "self-medication" to ameliorate depressive symptoms 
[7]. However, unhealthy lifestyles have been also longitudinally associated with depression. People who smoke [8] and drink excessively [9] are more likely to become depressed over time. This could be explained by the existence of common vulnerable factors independently associated with depression and with unhealthy lifestyles $[10,11]$. However, a more direct relationship between some unhealthy lifestyles and depression has been also suggested. For example, tobacco might impact on some biological mechanisms that could increase the likelihood of developing depression $[7,12]$.

Existing evidence might also support that once unhealthy lifestyles and/or depression are present they might exacerbate one another. A chronic course of depression has been associated with an incidence of excessive alcohol use and with an increase in cigarette smoking [5] whereas, depressed people who smoked [8] were more likely to remain depressed over time.

A previous study reported that the highest prevalence of unhealthy lifestyles was found in concurrent depressed people, followed by lifetime depressed and never depressed [4]. However, it remains unclear whether a higher prevalence of unhealthy lifestyles is found in people with persistent depression compared to incident depression.

In contrast to the results reported in the Western literature, one study from China [13] found that smokers were less likely to develop and maintain depressive symptoms over time and that alcohol drinkers were at lower likelihood for developing depression. No other longitudinal studies to our knowledge, have studied the longitudinal relationship between unhealthy lifestyles and depression in emerging countries where depression is also related to poor population health measures, such as years lived with disability [14].

The study of lifestyles and their relationship with depression is particularly important in the middle-income countries. Firstly, because their economic growth has facilitated a rapid spread of unhealthy lifestyles, but national health policies have not responded as quickly to efficiently tackle them [15]. Secondly, because the relationship between unhealthy lifestyles and depression might work differently in emerging countries than in high income countries, since unhealthy lifestyles might be associated with different social circumstances; For example, high level of physical activity is associated with higher level of education in high income countries, whereas the opposite direction might be found in emerging countries [16], and finally, these factors can be modifiable by community-based interventions [17] which are convenient actions in the particular context of emerging countries, where the specialized mental health care coverage is still sparse [18].

Therefore, the present study aims to fill a gap in the literature by determining i) whether people with incident depression and persistent depression significantly differ in their prevalence of unhealthy lifestyles ii), whether people with unhealthy lifestyles are more likely to develop depression, and finally iii) whether people with depression and unhealthy lifestyles are more likely to remain depressed over time.

\section{Methods \\ Design}

The data are from four of the countries participating in the World Health Organization's Study on Global AGEing and Adult Health (SAGE), a multi-country longitudinal study. These countries have been all classified as middle-income countries according to the World Bank classification [19].

\section{Sample and study procedures}

SAGE study collected nationally representative samples of adults aged 50 years and older, and a smaller comparative sample of those 18-49 years in age. SAGE Wave 0 [20] was conducted between 2002-2004 and Wave 1 between 2007-2010. A subsample of SAGE Wave 0 respondents were revisited in SAGE Wave 1 in Ghana, India, Mexico, and the Russian Federation, resulting in a longitudinal data set of 7908 respondents in total. In India, all respondents aged 50 years and older were revisited in Wave $1(n=4888)$. In Ghana $(n=544)$, Mexico $(n=1876)$, and the European region of the Russian Federation $(n=600)$, a sub-set was randomly selected for the follow-up. The data from Waves 0 and 1 were linked based on unique household and individual identifiers, location, age and sex. Individual response rates for SAGE Wave 0 were $95 \%$ in Ghana, $94 \%$ in India, $100 \%$ in Mexico and $99 \%$ in the Russian Federation. Response rates for SAGE Wave 1 were $84 \%$ in the Russian Federation, $81 \%$ in Ghana and $68 \%$ in India and 53\% in Mexico. The questions were translated into the local languages following the WHO translation guidelines for assessment instruments, which included a forward translation, a targeted backtranslation, a review by a bilingual expert group and a detailed translation report [21]. Face-to-face interviews were conducted at the respondents' homes by trained interviewers. Further details of the design and methods have been published elsewhere [22].

Ethical approvals from the following institutions were obtained: Ethics Review Committee, World Health Organization; Ethical Committee, Ghana Medical School, Accra, Ghana; Institutional Review Board, International Institute of Population Sciences, Mumbai, India; Ethics Committee, National Institute of Public Health (INSP), Cuernavaca, Mexico; and Ethics Committee, OPM (School of Preventive and Social Medicine), Russian Academy of Medical Sciences, Moscow, Russia. Written informed consent from each participant was also obtained. 


\section{Study instruments}

Presence of 12-month depressive episode was based on the International Classification of Diseases, Tenth Revision (ICD-10) diagnostic criteria for research for depressive episodes [23], and was derived from an algorithm that took into account respondents reporting symptoms of depression during the previous 12 months [24]. Individuals were additionally asked whether they had ever been diagnosed with depression by a health professional or had ever taken medication or received some other treatment (e.g. psychotherapy). Participants who experienced 12-month depression in Wave 1 but did not report having experienced lifetime depression in Wave 0 were defined as the incident depression group. In turn, respondents who reported 12-month depression at both waves were defined as the persistent depression sample.

Alcohol consumption was assessed by the question, "Have you ever consumed a drink that contains alcohol (such as beer, wine, spirits, etc.)?" Those who answered "no" were categorized as "never" drinkers. For those answering "yes", a separate question was asked about how many drinks of any alcohol beverage they had taken on each day of the previous week. Heavy drinkers were defined as those who consumed at least five (for men) or four (for women) standard alcoholic drinks per day on at least one day in the week before the interview [25]. Nonheavy drinkers were defined as any respondent who have ever consumed alcohol but were not heavy drinkers.

Current smoking was defined as a binary variable indicating whether the respondent currently smoked any tobacco product. Current smokers were categorized into "non-daily smokers" and "daily smokers" if the respondent reported to be an occasional smoker or to smoke on a daily basis, respectively. Although the use of smokeless tobacco is known to cause health problems, its use was only collected in Wave 0 in the countries where smokeless tobacco was a relevant issue, such as India. For data comparability reasons with the rest of the countries, individuals who only used smokeless tobacco were excluded from analyses.

Physical activity was measured with the International Physical Activity Questionnaire (IPAQ): short form [26] in Wave 0 and with the Global Physical Activity Questionnaire (GPAQ) in Wave 1 [27]. Physical activity scores were categorized into high, moderate and low physical activity $[26,27]$.

Presence of at least one of the following chronic physical conditions was obtained: arthritis, asthma, angina pectoris, and diabetes. Individuals were considered to have the health condition when they had been diagnosed with it at some point and had taken medication or some other treatment for it. Additionally, respondents were also identified to have arthritis, asthma or angina if they reported the presence of the core symptoms of the condition during the previous 12 months using diagnostic algorithms that have been used previously [28].

Body mass index (BMI) was used to assess underweight, normal weight, overweight and obesity. Using the standard WHO definition, BMI was categorized as $<18.5 \mathrm{~kg} / \mathrm{m}^{2}$ (underweight), 18.5-24.9 kg/m² (normal weight), $\geq 25.0 \mathrm{~kg} /$ $\mathrm{m}^{2}$ (overweight / obesity).

Health status was assessed with a set of health-related questions covering eight health domains: mobility, selfcare, pain and discomfort, cognition, interpersonal activities, vision, sleep and energy, and affect [29]. For each question, the responses were recorded on a 5-point scale ranging from no difficulty/problem to extreme difficulty. An overall health status score based on these healthrelated questions was obtained using a Rasch model [30]; the health status scores ranged from 0 to 100, with higher scores indicating better health.

Socio-demographic information, including age, gender, education level, employment, and country-specific household income were reported at the beginning of the interview. The country-specific household income was estimated for each respondent using an assets-based approach [31]. The index was further divided into quintiles within each country, where quintile one represented the poorest wealth quintile and quintile five the richest.

\section{Data analysis}

Firstly, the percentages of people with incidence and persistence of depression were calculated. Incidence was calculated dividing the number of people with 12-month depression in Wave 1 by the number of people without lifetime depression in Wave 0. Persistence of depression was calculated dividing the number of people with 12month depression in Wave 1 by the number of people with 12-month depression in Wave 0.

General characteristics of respondents with incident depression and persistent depression in Wave 1 were described. Pairwise comparisons between these groups (people with incident depression and people with persistent depression) were undertaken by a $t$-test for continuous variables and chi-square tests for categorical variables. Cohen's d and Cramer's V were calculated as effect sizes for significant differences found in t-tests and chi-square tests, respectively.

To check whether baseline characteristics were associated with missing data on 12-month depression in Wave 1 , pairwise comparisons between participants with and without missing values were undertaken by $\mathrm{t}$-tests and chi-square tests for continuous and categorical variables, respectively. Effect sizes were also calculated in case of significant differences.

A first logistic regression analysis including 12-month depression in Wave 1 as an outcome variable was undertaken to estimate whether baseline unhealthy lifestyles 
were predictive of incident depression. For this first analysis, people with lifetime depression at Wave 0 were excluded, leaving an analytical sample of 6349 persons. Unhealthy lifestyles were included as the main predictors. This analysis was also controlled for demographics, presence of a physical chronic condition, BMI, general health status and country.

Finally, a second logistic regression analysis, but including people with 12-month depression in Wave 0 , was undertaken to estimate factors longitudinally associated with persistent depression.

Odds Ratio (OR) and 95\% confidence intervals (95\% CI) were displayed for the logistic regressions. Results were considered statistically significant when $p \leq 0.05$. Statistical analyses were conducted using Stata version 11.

\section{Results}

\section{General characteristics of the sample}

Table 1 includes baseline general characteristics of respondents with persistent depression, with incident depression in Wave 1 and pairwise comparisons between these two groups. A total of 594 adults out of the 5970 participants without lifetime depression in Wave 0 (10.0\%) were classified as having incident depression in Wave 1. A total of 219 adults out of the 1267 participants who experienced 12-month depression in Wave 0 (26.4\%) were classified with depression at both time points (persistent depression). In comparison to adults with incident depression in Wave 1, those with persistent depression were more frequently women, suffered more frequently from at least one chronic physical health condition and experienced lower health status. No significant differences were found in the baseline frequencies of smoking, physical activity and heavy alcohol use between people with incident depression in Wave 1 and people with persistent depression in Wave 1 (Table 1).

\section{Analyses with missing values on the outcome variable} Older people in Wave $0(t(7896)=3.33 ; p<0.001 ; \mathrm{d}=0.16)$, participants from Ghana $\left(\chi^{2}(3)=13.23(3), p=0.004, \mathrm{~V}=\right.$ $0.05)$ and people who suffered from any chronic health condition in Wave $0\left(\chi^{2}(1)=208.47, p=0.004, \mathrm{~V}=0.05\right)$ showed higher missing values on 12-month depression in Wave 1. However, Cramer's V was lower than 0.20 in all cases, indicating a very low effect size according to Cohen's guidelines [32].

\section{Unhealthy lifestyles and incidence of depression}

Table 2 shows the baseline risk factors for incident 12-month depression in Wave 1 . Results revealed that older persons and respondents with at least one chronic health condition were at higher risk for incident depression in Wave 1. Regarding the unhealthy patterns, nondaily and daily smokers were at higher risk for incident
Table 1 Sample characteristics by depression status in SAGE Wave 1

\begin{tabular}{|c|c|c|c|}
\hline Baseline variables & $\begin{array}{l}\text { Persistent } \\
\text { depression }\end{array}$ & $\begin{array}{l}\text { Incident } \\
\text { depression }\end{array}$ & $p^{1}(E . S)^{2}$ \\
\hline Age n (\%) Mean (SD) & $51.38(14.77)$ & $50.24(15.39)$ & 0.82 \\
\hline Women, n (\%) & $161(75.23)$ & $395(66.50)$ & $0.018(0.08)$ \\
\hline Unemployed, n (\%) & $73(50)$ & $180(40.91)$ & 0.060 \\
\hline Country, n (\%) & & & 0.37 \\
\hline Mexico & $80(37.38)$ & $203(34.18)$ & \\
\hline Ghana & $4(1.87)$ & $25(4.21)$ & \\
\hline Russia & $6(2.80)$ & $21(3.54)$ & \\
\hline India & $124(57.94)$ & $345(58.1)$ & \\
\hline Household income, n (\%) & & & 0.21 \\
\hline $1^{\text {th }} \& 2^{\text {nd }}$ quintile & 89 (41.59) & $218(36.7)$ & \\
\hline $3^{\text {rd }}, 4^{\text {th }} \& 5^{\text {th }}$ quintile & $125(58.41)$ & $376(63.30)$ & \\
\hline Education, n (\%) & & & 0.65 \\
\hline Less than primary & $92(42.99)$ & $244(41.22)$ & \\
\hline At least primary completed & $122(57.01)$ & $348(58.78)$ & \\
\hline Health conditions, n (\%) & & & $<0.001(0.23)$ \\
\hline None & $56(30.11)$ & $293(55.81)$ & \\
\hline At least one & $130(69.89)$ & $232(44.19)$ & \\
\hline $\begin{array}{l}\text { Global health score, } \\
\text { Mean (SD) }\end{array}$ & $60.15(10.01)$ & $70.10(14.22)$ & $<0.001(0.75)$ \\
\hline Alcohol n (\%) & & & 0.98 \\
\hline Never drinkers & $151(92.07)$ & $449(92.20)$ & \\
\hline Current drinkers & $10(6.10)$ & $31(6.35)$ & \\
\hline Heavy drinkers & $3(1.83)$ & $8(1.64)$ & \\
\hline Current smoking n (\%) & & & 0.51 \\
\hline No current smokers & $137(65.24)$ & $400(69.57)$ & \\
\hline No-daily smokers & $16(7.62)$ & $37(6.43)$ & \\
\hline Daily smokers & $57(27.14)$ & $138(24.0)$ & \\
\hline BMI n (\%) & & & 0.72 \\
\hline Normal weight & $119(71.69)$ & $355(70.44)$ & \\
\hline Underweight & $21(12.65)$ & $76(15.08)$ & \\
\hline Overweight/obese & $26(15.66)$ & $73(14.48)$ & \\
\hline Physical exercise n (\%) & & & 0.25 \\
\hline Highly active & $135(63.08)$ & $381(64.14)$ & \\
\hline Moderately active & $23(10.75)$ & $84(14.14)$ & \\
\hline Inactive & $56(26.17)$ & $129(21.72)$ & \\
\hline
\end{tabular}

${ }^{1} p$-value associated to differences among sets using Chi-squared test (categorical variables) or $t$ test (continuous variables)

${ }^{2}$ Effect size measure. Cramer's $V$ for Chi-squared tests and Cohen's $d$ for $T$ test

depression in Wave 1, compared with never-smokers. The risk of an incident depression in the follow-up was higher among underweight adults in comparison with the normal BMI range group. Similarly, the presence of at least one chronic health condition in baseline was related to the depression in Wave 1. Health status, gender, employment 
Table 2 Odds ratios for the association between baseline risk factors and incident and persistent depression in SAGE Wave 1 (2007/10)

\begin{tabular}{|c|c|c|c|c|}
\hline \multirow[t]{2}{*}{ Baseline risk factors $^{\mathrm{a}}$} & \multicolumn{2}{|c|}{ Persistent depression } & \multicolumn{2}{|c|}{ Incident depression } \\
\hline & O.R. $(95 \% \mathrm{Cl})$ & $p$ & O.R. $(95 \% \mathrm{Cl})$ & $p$ \\
\hline Sex (ref. men) & $0.88(0.49,1.59)$ & 0.69 & $1.15(0.84,1.57)$ & 0.37 \\
\hline Age & $0.99(0.98,1.01)$ & 0.61 & $1.02(1.00,1.02)$ & $<0.001$ \\
\hline Unemployed (ref. employed) & $1.25(0.75,2.09)$ & 0.39 & $0.75(0.63,1.11)$ & 0.22 \\
\hline Education (ref. less than primary) & $0.82(0.49,1.38)$ & 0.47 & $0.78(0.59,1.04)$ & 0.087 \\
\hline Household income (ref. quintile $3^{\text {rd }}, 4^{\text {th }}$ and $5^{\text {th }}$ ) & $0.61(0.39,0.94)$ & 0.027 & $0.87(0.68,1.12)$ & 0.29 \\
\hline \multicolumn{5}{|l|}{ Current smokers (ref. not-current smoker) } \\
\hline Non-daily smokers & $0.38(0.05,2.99)$ & 0.36 & $2.06(1.18,3.62)$ & 0.011 \\
\hline Daily smokers & $0.93(0.55,1.57)$ & 0.80 & $1.46(1.09,1.97)$ & 0.012 \\
\hline \multicolumn{5}{|l|}{ Alcohol consumption (ref. never drinkers) } \\
\hline Non-heavy drinkers & $0.98(0.36,2.61)$ & 0.96 & $0.93(0.57,1.52)$ & 0.78 \\
\hline Heavy drinkers & $4.72(1.03,21.72)$ & 0.040 & $1.59(0.67,3.75)$ & 0.29 \\
\hline \multicolumn{5}{|l|}{ Physical inactive (ref. high active) } \\
\hline Moderate physical activity & $0.59(0.23,1.48)$ & 0.26 & $0.97(0.66,1.42)$ & 0.89 \\
\hline Low physical activity & $2.11(1.24,3.59)$ & 0.006 & $1.23(0.89,1.68)$ & 0.20 \\
\hline \multicolumn{5}{|l|}{ BMI (ref. normal range) } \\
\hline Underweight & $0.64(0.36,1.15)$ & 0.14 & $1.45(1.07,1.96)$ & 0.016 \\
\hline Overweight/obese & $1.48(0.75,2.89)$ & 0.26 & $0.99(0.68,1.00)$ & 0.97 \\
\hline Chronic condition (ref. none) & $1.28(0.78,2.10)$ & 0.32 & $1.32(1.02,1.72)$ & 0.034 \\
\hline Global health & $0.92(0.96,1.00)$ & 0.11 & $0.99(0.98,1.00)$ & 0.14 \\
\hline
\end{tabular}

${ }^{a}$ Analyses were controlled by country (Mexico was the reference category)

status, obesity/overweight, alcohol consumption patterns and physical activity levels were not related to incident depression in Wave 1 .

\section{Unhealthy lifestyles and persistence of depression}

Table 2 also reports risk factors for experiencing 12month depression at both time points. Participants with medium-high household income were at lower risk for persistent depression in comparison with those who ranked in the two lower household income quintiles. Regarding unhealthy lifestyles, baseline heavy drinkers were at higher risk for persistent depression in comparison with abstainers. In addition, people with low physical activity at baseline were at higher risk for persistent depression in comparison with those having high physical activity level. Baseline health status, presence of chronic diseases, BMI and smoking were not related to persistent depression.

\section{Discussion}

To our knowledge, this is one of the few studies to analyze longitudinal relationships between unhealthy lifestyles and depression using data from four emerging countries: India, Chana, Mexico and Russia.

Firstly, baseline frequencies of unhealthy lifestyles between people who developed depression in Wave 1 and people with depression in both waves were not significantly different. These results are not congruent with a previous study showing a dose-response relationship between history of depression and the higher prevalence of smoking, physical inactivity and heavy drinking. [4] Nonetheless, this latter study was crosssectional and did not analyse chronicity. The fact that unhealthy lifestyles were similar between people with depression and people who prospectively developed depression did not support the hypothesis of "selfmedication" of depressive symptoms. In turn, these results might be in line with the existence of common vulnerable factors between depression and unhealthy lifestyles. However, our results do not allow us to completely reject the self-medication hypothesis. People who developed depression in Wave 1 might have experienced subthreshold symptoms of depression in Wave 0 , which can be also associated with distress and disability [33]. Further studies with weighted prevalence estimations are necessary to confirm these results.

Regarding the factors associated with the onset of depression in Wave 1, the results show that baseline daily smoking was associated with depression in Wave 1. This finding is in line with the previous literature collected in high income countries $[10,34]$. One study reported that the relationship between tobacco use and depression might be both direct and indirect [10]. Several shared genetic factors have been found between depression and 
tobacco use [35]. In addition, some authors have suggested that specific inflammation markers possibly triggered by tobacco use and that are also correlated with the onset of depression could also explain the relationship between tobacco and depression [36]. However, the study of the mediating role of inflammation markers between unhealthy lifestyles and depression needs to be further explored [12]. In addition, other authors in China found that smokers were at lower risk for depression than never smokers [13]. These contradictory findings might be explained by methodological differences in the measurement of tobacco use and in the control for confounders since this last study did not consider the effect of income or the presence of chronic health conditions. One study suggested that there are also environmental factors in the relationship between tobacco and depression and that their importance might vary based on age participants [35]. Further longitudinal studies should be conducted in emerging countries to confirm whether there are specific cultural factors explaining the relationship between tobacco use and depression. Although our study is longitudinal and we restricted our analyses to people who neither experienced 12 months depressive symptoms in baseline nor were previously diagnosed with depression, reversed causality (i.e. depression leading to tobacco use) cannot be completely ruled out, since smokers in baseline could have experienced an undiagnosed depressive episode prior to Wave 0 which could make them more likely to smoke [4].

The present study also found that the non-daily smoking group was more likely to experience depression in Wave 1 than the daily smoking group in comparison with never smokers. This finding is not in accordance with the previous literature reporting that heavy smokers are more likely to be depressed than light smokers [34]. However, another study suggested that relationship between higher frequency of tobacco use and depression was only significant in younger ages [37]. On the other hand, non-daily smoking has been correlated to depression, specifically in women [38]. Further studies should confirm whether non-daily smokers are the highest risk group for depression, including gender-and-age-specific analyses.

Nearly $80 \%$ of the world's tobacco users are located in low-and-middle-income countries [39]. Our results suggest that daily and no daily smokers were more likely to become depressed over time. Therefore, health care providers in emerging countries can benefit from this line of study if further research can check whether smoking cessation can reduce depression in emerging countries as it has been reported in high income countries [40].

Additionally, our analyses also examined whether people with depression and unhealthy lifestyles in Wave 0 were more likely to continue having depression in Wave 1. Heavy drinkers that were depressed in baseline were more likely to still be depressed in the follow-up. This is in line with studies conducted in higher-income countries where heavy drinking has been associated with both recurrent and chronic depression [41, 42]. However our study did not consider the temporal sequence between heavy drinking and depression therefore, we cannot assure whether heavy alcohol drinking was a risk factor for persistent depression or if on the contrary, it was chronic depression that increased the likelihood of becoming heavy drinker [5].

Similarly, depressed participants with lower physical activity were more likely to also be depressed in the follow-up. This finding is congruent with previous studies [43]. Some evidence supports increased physical activity levels for those with depression to reduce residual symptoms and prevent further relapses [44]. However, this finding might also be explained by the fact that people with low physical activity might also suffer from higher severity of depression, which has also been related to a worse course of depression [45]. Our study was not able to assess when physical activity and depression emerged, consequently we cannot assure whether lower physical activity was a risk factor for chronicity of depression or whether people with chronic depression are persistently physical inactive [5]. Further studies should confirm whether a chronic course of depression is associated with a drop in physical activity, including time-varying factors models.

Finally, in contrast to previous evidence, our study did not find that depressed smokers were more likely to continue having depression in Wave 1 [8]. Further studies should check whether a more chronic course of depression might increase tobacco use [5] and also whether persistent smokers are more likely to experience acute episodes of depression.

The main strengths of the present study are the use of the same methodology and the same evaluation instruments in a large longitudinal study including four different countries and the control for important confounders in the statistical analyses. Nevertheless, our results also need to be interpreted taking into account some limitations. The diagnosis of depression was made using fully structured, trained, lay interviewers rather than clinician-administered interviews. Nevertheless, the clinical SCIDCIDI reappraisal interviews have shown a good concordance in the Diagnostic and Statistical Manual of Mental Disorders diagnoses (DSM) [46]. Another limitation of the present work is the lack of a rating scale measure to assess the severity of depression. We also acknowledge that some people who screened negative for lifetime depression in Wave 0 might have experienced a previous depressive episode that may have gone unrecognized or untreated. Nonetheless, our study did not aim to estimate the impact of unhealthy lifestyles on incidence of first-time 
occurrences of depression, but rather the role of these modifiable factors on the subsequent development of depression among those who had neither a depressive episode in the 12 months preceding the baseline assessment nor a previous lifetime depression diagnosis. In addition, the data did not allow us to differentiate whether 12-month depression in Wave 1 was really a recurrent episode with an interim period of remission, or a nonremitting course of the 12-month depressive episode collected in Wave 0 . Further studies, including more frequent measurement or questions about the period between the two waves, could address the role of unhealthy behaviours in the clinical course of depression, differentiating between non-remitting or recurrent depressive episodes. Finally, three baseline factors were associated with missing information. However, the effect sizes of these differences were small.

\section{Conclusions}

The present study provides evidence collected in four emerging countries about the positive relationships between some unhealthy lifestyles and depression. In this study, daily and non-daily smokers were both more likely to become depressed over time. The results of this study together with the studies undertaken in high income countries might support the idea of common mechanisms explaining the relationship between tobacco use and depression across countries. However, further studies are still necessary to understand this relationship. In addition, this study also suggests that depressed people with low physical activity and with heavy drinking patterns were both more likely to continue having depression over time. Further studies should confirm whether unhealthy lifestyles are risk factors for a chronic course of depression or the other way around. Health care providers from emerging countries should consider unhealthy lifestyles in patients with depression. Further studies could check whether the management of healthy lifestyles might also help to prevent and improve depression in emerging countries.

\section{Abbreviations}

BMI: Body mass index; SAGE: Study on Global AGEing and Adult Health; WHO: World Health Organization

\section{Acknowledgements \\ The authors gratefully acknowledge the immense contribution of the research participants, without whom this study would not have been possible. We would also like to acknowledge the principal investigators at the SAGE sites for both waves_-P. Arokiasamy (India), R. Biritwum (Ghana), R. Lopez Ridaura (Mexico), and T. Maximova (Russian Federation)—and their study teams.}

\section{Funding}

This paper uses data from the WHO's Study on Global AGEing and Adult Health (SAGE). SAGE is supported by the US National Institute on Aging through Interagency Agreements (OGHA 04034785; YA1323-08-CN-0020; Y1AG-1005-01) and through a research grant (R01-AG034479). The research leading to these results has received funding from the People Programme
(Marie Curie Actions) of the European Union's Seventh Framework Programme FP7/2007 - 2013 under grant agreement no 316795 (MARATONE project). The present work was also supported by the Centro de Investigacion Biomédica en Red en Salud Mental (CIBERSAM) and by the Instituto de Salud Carlos III - FIS research grant PI13/00059, which has been co-funded by the European Union European Regional Development Fund (ERDF) "A Way to Build Europe". This study was also supported by the European Union's Seventh Framework Programme (FP7/2007-2013) under grant agreement $n^{\circ}$ 305968 (EMERALD project).

The views expressed in this paper are those of the authors, and do not necessarily represent the views or policies of the World Health Organization.

\section{Availability of data and materials}

The datasets analysed during the current study are available in the WHO Multi-Country Studies Data Archive repository, [http://apps.who.int/ healthinfo/systems/surveydata/index.php/catalog]

\section{Authors' contributions}

MC wrote the first draft of the manuscript, MM searched literature, FFC performed the statistical analyses, SC was the study coordinator and designed the original study protocol, NN and PK contributed to data curation, project administration and to create study variables, CD'E contributed to methodology and to analyze data, JLM provided the original idea of the manuscript and supervised the whole process. All the authors made a substantial contribution to the writing \& reviewing process of the manuscript and approved its final version.

\section{Competing interests}

The authors declare that they have no competing interests.

\section{Consent for publication}

Not applicable.

\section{Ethics approval and consent to participate}

Ethical approvals from the following institutions were obtained: Ethics Review Committee, World Health Organization; Ethical Committee, Ghana Medical School, Accra, Ghana; Institutional Review Board, International Institute of Population Sciences, Mumbai, India; Ethics Committee, National Institute of Public Health (INSP), Cuernavaca, Mexico; and Ethics Committee, OPM (School of Preventive and Social Medicine), Russian Academy of Medical Sciences, Moscow, Russia. Written informed consent from each participant was also obtained.

\section{Author details}

${ }^{1}$ Centro de Investigación Biomédica en Red de Salud Mental. CIBERSAM, Instituto de Salud Carlos III, Madrid, Spain. ${ }^{2}$ Department of psychiatry, Universidad Autónoma de Madrid, Madrid, Spain. ${ }^{3}$ Department of Health Statistics and Information Systems, World Health Organization, Geneva, Switzerland. ${ }^{4}$ Research Centre for Generational Health and Ageing, Faculty of Health, University of Newcastle, Newcastle, NSW, Australia. ${ }^{5}$ National Centre for Epidemiology and Population Health (NCEPH), Australian National University, Canberra, ACT, Australia. ${ }^{6}$ Hospital Universitario de La Princesa, Instituto de Investigación Sanitaria Princesa (IIS Princesa), Diego de Leon, 62, Madrid 28006, España.

Received: 19 November 2016 Accepted: 15 February 2017

Published online: 20 March 2017

\section{References}

1. World Health Organization. Global health risks: mortality and burden of disease attributable to selected major risks. Geneva: World Health Organization; 2009.

2. World Health Organization. Global status report on noncommunicable diseases 2014. Geneva: WHO Press; 2014.

3. Velten J, Lavallee KL, Scholten S, Meyer AH, Zhang X-C, Schneider S, Margraf J. Lifestyle choices and mental health: a representative population survey. BMC Psychol. 2014;2:1.

4. Strine TW, Mokdad AH, Dube SR, Balluz LS, Gonzalez O, Berry JT, Manderscheid R, Kroenke K. The association of depression and anxiety with obesity and unhealthy behaviors among community-dwelling US adults. Gen Hosp Psychiatry. 2008;30:127-37.

5. Van Gool CH, Kempen Gl, Penninx BW, Deeg DJ, Beekman AT, Van Eijk JT. Relationship between changes in depressive symptoms and unhealthy 
lifestyles in late middle aged and older persons: results from the Longitudinal Aging Study Amsterdam. Age Ageing. 2003;32:81-7.

6. McCarty CA, Kosterman R, Mason WA, McCauley E, Hawkins JD, Herrenkohl TI, Lengua $L$ J. Longitudinal associations among depression, obesity and alcohol use disorders in young adulthood. Gen Hosp Psychiatry. 2009;31:442-50.

7. Breslau N, Peterson EL, Schultz LR, Chilcoat HD, Andreski P. Major depression and stages of smoking: a longitudinal investigation. Arch Gen Psychiatry. 1998;55:161-6.

8. Bakhshaie J, Zvolensky MJ, Goodwin RD. Cigarette smoking and the onset and persistence of depression among adults in the United States: 1994-2005. Compr Psychiatry. 2015;60:142-8.

9. van Gool CH, Kempen Gl, Bosma H, van Boxtel MP, Jolles J, van Eijk JT. Associations between lifestyle and depressed mood: longitudinal results from the Maastricht Aging Study. Am J Public Health. 2007;97:887-94.

10. Boden JM, Fergusson DM, Horwood LJ. Cigarette smoking and depression: tests of causal linkages using a longitudinal birth cohort. Br J Psychiatry. 2010;196:440-6.

11. De Moor MH, Boomsma DI, Stubbe JH, Willemsen G, de Geus EJ. Testing causality in the association between regular exercise and symptoms of anxiety and depression. Arch Gen Psychiatry. 2008;65:897-905.

12. Hiles SA, Baker AL, de Malmanche T, McEvoy M, Boyle M, Attia J. Unhealthy lifestyle may increase later depression via inflammation in older women but not men. J Psychiatr Res. 2015;63:65-74

13. Cheng HG, Chen S, McBride O, Phillips MR. Prospective relationship of depressive symptoms, drinking, and tobacco smoking among middle-aged and elderly community-dwelling adults: Results from the China Health and Retirement Longitudinal Study (CHARLS). J Affect Disord. 2016;195:136-43.

14. Murray CJ, Vos T, Lozano R, Naghavi M, Flaxman AD, Michaud C, Ezzati M, Shibuya K, Salomon JA, Abdalla S. Disability-adjusted life years (DALYS) for 291 diseases and injuries in 21 regions, 1990-2010: a systematic analysis for the Global Burden of Disease Study 2010. Lancet. 2013;380:2197-223.

15. Lachat C, Otchere S, Roberfroid D, Abdulai A, Seret FMA, Milesevic J, Xuereb G, Candeias V, Kolsteren P. Diet and physical activity for the prevention of noncommunicable diseases in low-and middle-income countries: a systematic policy review. PLoS Med. 2013;10:e1001465.

16. Teo K, Lear S, Islam S, Mony P, Dehghan M, Li W, Rosengren A, Lopez-Jaramillo P, Diaz R, Oliveira G. Prevalence of a healthy lifestyle among individuals with cardiovascular disease in high-, middle-and low-income countries: the Prospective Urban Rural Epidemiology (PURE) study. JAMA. 2013;309:1613-21.

17. World Health Organization. Reducing risks and preventing disease: populationwide interventions. In: Global status report on noncommunicable diseases. Geneva: WHO press; 2010.

18. World Health Organization. mhGAP: Mental Health Gap Action Programme: scaling up care for mental, neurological and substance use disorders. Geneva: WHO press; 2008.

19. World Bank. World Development Indicators: http://data.worldbank.org/datacatalog/world-development-indicators. Accessed 16 Nov 2016.

20. Üstün T, Ayuso-Mateos JL, Chatterji S, Mathers C, Murray CJ. Global burden of depressive disorders in the year 2000. Br J Psychiatry. 2004;184:386-92.

21. World Health Organization. Process of translation and adaptation of instruments. http://www.who.int/substance_abuse/research_tools/ translation/en/. Accessed 16 Mar 2017.

22. Kowal P, Chatterji S, Naidoo N, Biritwum R, Fan W, Lopez Ridaura R, Maximova T, Arokiasamy P, Phaswana-Mafuya N, Williams S, et al. Data resource profile: the World Health Organization Study on global AGEing and adult health (SAGE). Int J Epidemiol. 2012:41:1639-49.

23. World Health Organization. The ICD-10 Classification of Mental and Behavioural Disorders: Diagnostic Criteria for Research. Geneva: World Health Organization; 1993.

24. Kessler RC, Üstün TB. The world mental health (WMH) survey initiative version of the world health organization (WHO) composite international diagnostic interview (CIDI). Int J Methods Psychiatr Res. 2004;13:93-121.

25. World Health Organization. International guide for monitoring alcohol consumption and related harm. Geneva: World Health Organization; 2002

26. IPAQ Research Committee. Guidelines for data processing and analysis of the International Physical Activity Questionnaire (IPAQ)-short and long forms. Version 2.0. April 2004. http://www.institutferran.org/documentos/ scoring short_ipaq_april04.pdf. Accessed 16 Mar 2017.

27. World Health Organization. Global physical activity questionnaire (GPAQ) analysis quide. Geneva: World Health Organization; 2012.
28. Moussavi S, Chatterji S, Verdes E, Tandon A, Patel V, Ustun B. Depression, chronic diseases, and decrements in health: results from the World Health Surveys. Lancet. 2007;370:851-8.

29. Salomon JA, Mathers CD, Chatterii S, Sadana R, Ustun TB, Murray CJ. Quantifying individual levels of health: definitions, concepts and measurement issues. Geneva: World Health Organization; 2003.

30. Pallant JF, Tennant A. An introduction to the Rasch measurement model: an example using the Hospital Anxiety and Depression Scale (HADS). Br J Clin Psychol. 2007:46:1-18.

31. Ferguson B, Tandon A, Gakidou E, Murray C. Estimating permanent income using indicator variables. Geneva: World Health Organization; 2003.

32. Cohen J. Statistical power analysis for the behavioral sciences. Hillsdale: Erlbaum; 1988.

33. Rodriguez MR, Nuevo R, Chatterji S, Ayuso-Mateos JL. Definitions and factors associated with subthreshold depressive conditions: a systematic review. BMC Psychiatry. 2012;12:181

34. Klungsøyr O, Nygård JF, Sørensen T, Sandanger I. Cigarette smoking and incidence of first depressive episode: an 11-year, population-based follow-up study. Am J Epidemiol. 2006;163:421-32.

35. Tully EC, lacono WG, McGue M. Changes in genetic and environmental influences on the development of nicotine dependence and major depressive disorder from middle adolescence to early adulthood. Dev Psychopathol. 2010;22:831-48

36. Berk M, Jacka F. Preventive strategies in depression: gathering evidence for risk factors and potential interventions. Br J Psychiatry. 2012;201:339-41.

37. Mojtabai R, Crum RM. Cigarette smoking and onset of mood and anxiety disorders. Am J Public Health. 2013;103:1656-65.

38. Husky MM, Mazure CM, Paliwal P, McKee SA. Gender differences in the comorbidity of smoking behavior and major depression. Drug Alcohol Depend. 2008;93:176-9.

39. World Health Organization. WHO report on the global tobacco epidemic, 2015: Raising taxes on tobacco. Switzerland: World Health Organization; 2015. p. 103.

40. Taylor G, McNeill A, Girling A, Farley A, Lindson-Hawley N, Aveyard P. Change in mental health after smoking cessation: systematic review and meta-analysis. BMJ. 2014;348:g1151.

41. Coryell W, Endicott J, Keller MB. Predictors of relapse into major depressive disorder in a nonclinical population. Am J Psychiatry. 1991;148:1353-8.

42. Mueller TI, Lavori PW, Keller MB, Swartz A, Warshaw M, Hasin D, Coryell W, Endicott J, Rice J, Akiskal H. Prognostic effect of the variable course of alcoholism on the 10-year course of depression. Am J Psychiatry. 1994;151:701-6.

43. Boschloo L, Reeuwijk KG, Schoevers RA, Penninx BW. The impact of lifestyle factors on the 2-year course of depressive and/or anxiety disorders. Affect Disord. 2014;159:73-9.

44. Trivedi MH, Greer TL, Grannemann BD, Chambliss HO, Jordan AN. Exercise as an augmentation strategy for treatment of major depression. J Psychiatr Pract. 2006;12:205-13.

45. Kessing LV. Severity of depressive episodes according to ICD-10: prediction of risk of relapse and suicide. Br J Psychiatry. 2004;184:153-6.

46. Haro JM, Arbabzadeh Bouchez S, Brugha TS, De Girolamo G, Guyer ME, Jin R, Lepine JP, Mazzi F, Reneses B, Vilagut G. Concordance of the Composite International Diagnostic Interview Version 3.0 (CIDI 3.0) with standardized clinical assessments in the WHO World Mental Health surveys. Int J Methods Psychiatr Res. 2006;15:167-80

\section{Submit your next manuscript to BioMed Central and we will help you at every step:}

- We accept pre-submission inquiries

- Our selector tool helps you to find the most relevant journal

- We provide round the clock customer support

- Convenient online submission

- Thorough peer review

- Inclusion in PubMed and all major indexing services

- Maximum visibility for your research

Submit your manuscript at www.biomedcentral.com/submit 